\title{
Formação profissional de nível médio: o ensino médio integrado no Instituto Federal de Mato Grosso do Sul
}

\author{
High School Professional Formation: Integrated High School in Mato Grosso do Sul \\ Federal Institute
}
L'offer d'enseignement moyen integre dans l'état de Mato Grosso do Sul.
La formación para el nivel medio: Escuela construida en el Instituto Federal de Mato Grosso do Sul

\author{
Mirta Rie de Oliveira Tominaga* \\ (rietominaga@gmail.com) \\ Jefferson Carriello do Carmo** \\ (jefferson.carmo@prof.uniso.br)
}

Recebido em 30/04/2014; revisado e aprovado em 23/07/2014; aceito em 22/08/2014

DOI: http://dx.doi.org/10.1590/1518-70122015116

\begin{abstract}
Resumo: O objetivo deste trabalho é discutir a oferta de ensino médio integrado no estado de Mato Grosso do Sul tendo como foco os cursos do Instituto Federal de Mato Grosso do Sul, numa discussão que perpassa a questão da entrada dos cursos do Programa Nacional de Acesso ao Ensino Técnico e Emprego (Pronatec) no campo da formação profissional como um dos obstáculos à expansão do ensino médio integrado no estado.

Palavras-chave: Ensino Médio Integrado. Instituto Federal de Mato Grosso do Sul. Pronatec.

Abstract: This article aims to discuss the availability of integrated high school in the state of Mato Grosso do Sul focusing on the Mato Grosso do Sul Federal Institute courses. This discussions permeates the questions of the entry of the courses from the National Programe For Access To Technical Education and Employment (Pronatec) in the vocational trainning field as an obstacle for the expantion of integrated high school in the state.

Key words: Integrated High School. Mato Grosso do Sul Federal Institute. Pronatec.

Résumé: L'objectif de ce travail est la discussion sur l'offre d'enseignement moyen intégré, dans l'état de Mato Grosso do Sul, en mettant la lumière dans les cours du Instituto Federal de Mato Grosso do Sul. La question passe outre la question de l'entrée des cours du Programme national pour l'accès à l'éducation technique et de l'Emploi (Pronatec) dans le champ de la formation professionnelle comme l'un des obstacles à la diffusion de l'enseignement moyen intégré dans l'état.

Mots-clés: Enseignement Moyen Integre. Institute Federal du Mato Grosso do Sul. Pronatec.

Resumen: El objetivo de este trabajo es discutir la disponibilidad de la escuela secundaria integrada en el estado de Mato Grosso do Sul se centra en los cursos de la Escuela Politécnica Federal de Mato Grosso do Sul, una discusión que se respira en la cuestión de la entrada de los cursos del Programa Nacional para el Acceso a la Educación técnica y Empleo (Pronatec) en el campo de la formación profesional como un obstáculo para la expansión de la escuela secundaria integrada en el estado.

Palabras clave: Escuela Integrada. Instituto Federal de Mato Grosso do Sul. Pronatec.
\end{abstract}

\section{Introdução}

O trabalho entendido como emprego é um tema bastante discutido e difundido de modo que empresas especializadas em preparar jovens para esse fim e políticas públicas são criadas para formar profissionais a fim de atuarem no mercado de trabalho. O que pretendemos aqui é discutir sobre o ensino médio integrado no estado de Mato Grosso do Sul, tendo como foco os cursos no Instituto Federal de Mato Grosso do Sul (IFMS).

É sabido que muito precocemente os jovens brasileiros buscam inserir-se no mercado de trabalho, a fim de garantir o seu próprio sustento ou o sustento da família, sendo esse ingresso geralmente antes do término do ensino médio, muitos não chegando nem mesmo a concluir o ensino médio (POCHMANN, 2000).

A universalização do ensino médio no Brasil é uma questão ainda a ser resolvida, como afirma Saviani (2011), ainda há uma parcela muito pequena de jovens concluintes do ensino médio; para o autor, essa etapa escolar é a mais problemática de toda e estrutura do ensino, isso porque é a única etapa que oscila em suas reais funções, ou

\footnotetext{
* Universidade Católica Dom Bosco (UCDB), Campo Grande, MS, Brasil.

** Universidade de Sorocaba (UNISO), Sorocaba, SP, Brasil.
} 
seja, o ensino fundamental é claramente voltado para o ensino de cunho geral enquanto a educação superior é profissionalizante e, nesse ínterim, o ensino médio pende ora para um lado, ora para outro. Até o ano de 1970, ele era fundamentalmente propedêutico, com a reforma de 1971, a Lei 5.692 tornou-o totalmente profissionalizante. A reforma de 1990, mais especificamente o Decreto 2.208/97 buscou manter as duas funções, mas de forma separadas e mais recentemente, com o Decreto 5.154/04 seguido da Lei 11.741/08, busca-se uma integração entre as duas funções, propedêutica e profissional, mas ainda com as duas formas dadas pelo Decreto anterior, de formação profissional técnica com currículos separados do ensino médio.

O ensino médio, bem como a formação profissional de nível técnico podem ser analisados, portanto, sob dois enfoques. De um lado, como dois processos distintos, cada um com uma finalidade própria, mas dicotômicas entre si, um com o fim de preparar para o mercado de trabalho e outro com o fim de preparar para o prosseguimento dos estudos. De outro lado, podem ser entendidos como processos integrados que resultam em um único processo, integra ambas as funções, a de formação geral e profissional, com horizonte a uma formação integral do ser humano. No primeiro caso, o ensino médio é independente da educação profissional, não se relaciona com ela diretamente, tem como função principal a formação acadêmica, geral, para preparo do estudante para prosseguir nos estudos. No segundo caso, ensino médio e educação profissional são constituintes de um mesmo processo, de modo integrado, com finalidades que atendem tanto ao prosseguimento dos estudos em nível superior, como para formação profissional, tendo como eixo estruturante a ciência, o trabalho e a cultura.

Essas formas antagônicas e distintas de pensar o ensino médio e a formação profissional são históricas, ou seja, foram construídas historicamente gerando uma dualidade estrutural na educação brasileira, em dois grandes campos,

[...] aqueles das profissões manuais para os quais se requeria uma formação prática limitada à execução de tarefas mais ou menos delimitadas, dispensando-se os domínios dos respectivos fundamentos teóricos; e aqueles das profissões intelectuais para as quais se requeria domínio teórico amplo a fim de preparar as elites e representantes da classe dirigente para atuar nos diferentes setores da sociedade. (SAVIANI, 2011, p. 197).

\section{O estado de Mato Grosso do Sul}

Discutir sobre educação profissional implica discutir, mesmo que brevemente, sobre o contexto econômico de onde se fala. O espaço onde hoje é o estado de Mato Grosso do Sul, bem como a região Centro-Oeste, foi, segundo Abreu (2001), por muito tempo considerado como vazio demográfico e com vocações econômicas apenas para a agricultura e pecuária eminentemente voltadas para a subsistência. Passou a ser parte da política do governo federal a partir da década de 1970, como estratégia para a acumulação de capital, por meio de estratégias políticas de incorporação desse espaço ao território nacional, fato decorrente da crise do petróleo instalada em 1973, a qual teve, como resposta do governo brasileiro, o incentivo à exportação, ampliação da produção de produtos primários e a criação de condição para a substituição de importações em setores que se tornaram muito caros, como os fertilizantes, máquinas e equipamentos.

Em meados da década de 1980, segundo Abreu (2001), o Brasil, seguindo a conjuntura internacional, associado aos interesses do capital industrial, buscou explorar riquezas naturais ainda pouco exploradas e áreas com capacidade produtiva confirmada, com a aplicação de modernos insumos, no sentido de aumentar a produtividade imprimindo a verticalização da produção por meio da agroindústria. No espaço mato-grossense, surgiu o discurso de sua exploração, esse movimento ocorreu sustentado pelo slogan nova fronteira, que evoluiu logo para o de região solução. Esses discursos ocorreram no sentido de orientar a produção para exportação por meio da instalação de agroindústrias. Segundo a autora, esse processo foi uma espécie de "venda da região" para empreendedores do país e do mundo.

Segundo Casarotto (2013), nos últimos quinze anos, as exportações do estado de Mato Grosso do Sul apresentaram crescimento, tendo suas taxas médias anuais, superiores à do país, com importante participação do 
agronegócio nas exportações, embora venha sendo reduzida a participação do agronegócio, conforme crescem outros setores da economia, mas ainda assim é o principal setor exportador do estado, responsável em média por $80 \%$ de suas exportações anuais.

Para Casarotto (2013) a participação das exportações do agronegócio no estado passou por três momentos, o primeiro, de 1997 a 2004, com exportações de carne e do complexo soja; o segundo momento, a partir de 2005, com a participação do setor sucroalcooleiros, consolidando-se junto ao setores de carne e soja; e o terceiro momento, a partir de 2009, com a entrada da indústria da celulose.

Segundo os estudos de Galera (2011) sobre a atividade frigorífica de empresas brasileiras exportadoras de carne bovina, com a abertura comercial iniciada na década de 1990, mais especificamente na segunda metade da década de 2000, esse setor se inseriu no mercado global. No que tange ao estado de Mato Grosso do Sul, o processo de desconcentração de plantas produtivas do antigo centro Rio de Janeiro-São Paulo fez com que houvesse a relocalização dessas plantas para próximo das áreas de criação e engorda de gado. Esse fato contribuiu para que o estado passasse a alojar maior número de empresas dessa natureza, e nenhuma das empresas por ele investigadas tivesse origem no próprio estado, ou seja, todas vieram de outros locais, utilizando a estratégia lucrativa de instalar-se em regiões com grande concentração de gado.

Quanto à produção canavieira, Azevedo (2008) demonstra que o estado se encontra em plena expansão desse setor. No período de 1996 a 2008, foram vendidas ou efetuadas fusões de oito agroindústrias no estado, a maioria delas para ou com compradores ou parceiros de capitais internacionais ${ }^{1}$. Nesse mesmo período, o autor confirma que houve gradativa diminuição no ritmo de crescimento da cultura de soja e no montante de gado, o

\footnotetext{
${ }^{1}$ Das oito agroindústrias do Estado de Mato Grosso do Sul vendidas ou fundidas entre os anos de 1996 e 2008, seis foram para/com capitais estrangeiros: Usina Santa Olinda, 1996, José Pessoa; Alcovale, 2001, Unialco; Copernavi, 2005, Kidd \& Company; Passatempo, 2007, Louis Dreyfus; Maracaju, 2007, Louis Dreyfus; Esmeralda (projeto), 2007, Louis Dreyfus; Eldorado, 2008, Odebrecht e Monteverde Agroenergética, 2008, Bunge (AZEVEDO, 2008).
}

que para ele tem relação com o aumento da atividade canavieira: "a territorialização da atividade canavieira no estado de Mato Grosso do Sul e a sua crescente expansão aponta para um reordenamento territorial importante, que tende a mudar o perfil da produção agropecuária no Estado, com repercussões na produção de outras culturas" (AZEVEDO, 2008, p. 46).

Segundo Azevedo (2008), o que estimulou a expansão canavieira no Estado foi a elevação dos preços de açúcar e álcool nos últimos anos, além de outros aspectos que despertam interesse em grupos econômicos, tais como grande quantidade de terras para sustentar a expansão, com preços mais vantajosos que em outros locais com tradição na produção canavieira; organização sindical ainda frágil no setor; grande interesse das entidades públicas e privadas em sediar os empreendimentos, a exemplo dos incentivos fiscais concedidos por programas específicos do governo estadual.

Leite e Medeiros (2012, p. 85) afirmam que a generalização do termo agronegócio ${ }^{2}$ faz parte de um "esforço para reposicionar o lugar da agropecuária e investir em novas formas de produção" levando ao tratamento do setor "como dinâmico, moderno, produtor de divisas para o país, sustentáculo do desenvolvimento [esperando] romper com

\footnotetext{
${ }^{2} \mathrm{O}$ termo agronegócio surgiu recentemente no Brasil, segundo Leite e Medeiros (2012, p. 81), e tem relações com o termo norte-americano, agribusiness utilizado no Brasil a partir da década 1970, sendo traduzido como agroindústria e complexo industrial, destacando o processo de modernização e industrialização da agricultura. Segundo os autores, o termo agronegócio expressa as relações econômicas entre o setor agropecuário e a indústria, o comércio e os serviços e se relaciona com a "alta tecnologia agrícola" (LEITE; MEDEIROS, 2012, p. 84), mas, mesmo havendo redução da mão de obra no setor agrícola em função disso, o trabalho braçal assalariado está longe de desaparecer, pois mesmo as culturas não mecanizadas demandam esse tipo de mão de obra. Os autores mostram que há, no interior das unidades produtivas, "a presença de uma mão de obra qualificada, composta por operadores de máquinas, mecânicos, agrônomos, técnicos agrícolas [e a] reprodução de formas degradantes de trabalho. A tendência do agronegócio é "controlar áreas cada vez mais extensas do país e [...] concentração de empresas com controle internacional" (LEITE; MEDEIROS, 2012, p. 84). O estado de Mato Grosso do Sul é um exemplo da ligação entre o agronegócio e a disponibilidade de terras, é um estado que dispõe de terras para a expansão do agronegócio.
} 
a imagem do estritamente agrícola e com a imagem latifundiária" (LEITE; MEDEIROS, 2012, p. 86).

Segundo os autores, essa conceituação do agronegócio, ao se consolidar, faz emergir disputas com as forças sociais que o identificam como o "novo inimigo a ser combatido [...] ao modelo do agronegócio passa a ser contraposto o modelo agroecológico, pautado na valorização da agricultura camponesa e nos princípios da policultura" (LEITE; MEDEIROS, 2012, p. 87), isso porque a lógica do agronegócio consiste em produzir numa relação entre os setores, agropecuário, de serviços e de comércio, com o uso de alta tecnologia e vastas extensões de terras, o que leva ao entendimento de que há perspectivas desfavoráveis aos trabalhadores rurais e à agricultura familiar.
O estudo Análise das classes de renda rural em Mato Grosso do Sul (FAMASUL, 2012), encomendado pela Confederação de Agricultura e Pecuária do Brasil (CNA) realizado pelo Centro de Estudos Agrícolas da Fundação Getúlio Vargas (FGV), com o objetivo de analisar os perfis das classes de rendas rurais nos estados brasileiros, com base em dados do Censo Agropecuário 2006, mostra um pouco como no estado de Mato Grosso é feito o uso das terras e como ela é distribuída. O estudo sobre o estado de Mato Grosso do Sul demonstrou que há uma imensa discrepância entre as classes ${ }^{3}$ sociais, tanto no que se refere à renda líquida, quanto à participação destas no Valor Bruto da Produção (VBP), bem como na extensão média de terras destinada a cada uma das classes, conforme se pode observar na Tabela 1:

Tabela 1 - Classes de renda rural em Mato Grosso do Sul

\begin{tabular}{cccccc} 
Classes & $\begin{array}{c}\text { Estabelecimentos } \\
\text { rurais }\left(\mathrm{n}^{\circ}\right)\end{array}$ & $\begin{array}{c}\text { Renda líquida mensal } \\
(\mathrm{R} \$)\end{array}$ & $\begin{array}{c}\text { Área } \\
\text { média } \\
(\text { ha) }\end{array}$ & $\begin{array}{c}\text { Ocupação } \\
\text { do total de } \\
\text { terras }(\%)\end{array}$ & $\begin{array}{c}\text { Contribuição } \\
\text { anual no VBP }\end{array}$ \\
$\begin{array}{c}\text { agropecuária }(\%) \\
\text { A/B }\end{array}$ & 11.668 & acima de 4.083 & 1,7 mil & 65,8 & 91 \\
C & 10.804 & de $947,00-4.083,00$ & 314 & 11,2 & 6 \\
D/E & 32.787 & abaixo de 947 & 135 & 14,2 & 3 \\
\hline
\end{tabular}

Fonte: Federação da agricultura e pecuária de Mato Grosso do Sul (Famasul). Disponível em: http:/ / famasul. com.br/public/area-produtor/820-analise-das-classes-de-renda-rural-em-ms.pdf

Os dados do estudo, expostos na Tabela 1 , revelam que quase $70 \%$ das terras do estado estão nas mãos de aproximadamente $18 \%$ dos que detêm os estabelecimentos rurais e compõem as classes A e B, ao passo que aproximadamente $30 \%$ do total das terras analisadas são distribuídas entre as classes $C$ e $\mathrm{D} / \mathrm{E}$, sendo que a primeira, com quase três vezes menos estabelecimentos que a segunda, ocupa quase $50 \%$ das terras. A classe denominada D/E vive com uma renda que soma pouco mais que um salário mínimo, ou seja, não é difícil perceber que essa parcela social do campo produz em prol de sua própria sobrevivência, ao contrário dos grandes produtores que têm como objetivo final produzir mercadoria.

O que se pode concluir é que o estado de Mato Grosso do Sul tem uma imensa parcela de pequenos produtores e uma pequena parcela de grandes produtores, que contraditoriamente participam com quase $100 \%$ do VBP da agropecuária por disporem de elevado grau de desenvolvimento e tecnologia, o que leva a inferir-se que o processo de expansão do agronegócio tende a levar a classe de trabalhadores rurais a serem suprimidos pela necessidade de disponibilizar cada vez mais os seus espaços para a expansão do agronegócio.

É nesse contexto econômico e social que todo o movimento da implantação dos cursos de ensino médio integrado e dos cursos do Pronatec ocorre, num contexto em que a economia se move e demanda força de trabalho.

\footnotetext{
${ }^{3}$ As classes foram identificadas a partir da classe que se nomeou como $\mathrm{C}$, ou seja, a parcela rural com renda líquida (renda total menos despesas variáveis) de $\mathrm{R} \$$ 947,00 a R\$ 4.083,00 mensais; as classes A e B foram identificadas como a parcela que tem renda acima de $\mathrm{R} \$ 4.083,00$ mensais; e as classes $\mathrm{D}$ e E, a parcela com renda abaixo de $\mathrm{R} \$ 947,00$. A partir dessa delimitação a pesquisa trabalhou com mais duas variáveis: o numero de estabelecimentos rurais no estado por classes de renda e o VBP gerado por cada uma das classes (FAMASUL, 2012).
} 


\section{$3 \mathrm{O}$ ensino médio integrado: marcos legais e conceituais}

Até o ano de 1997, quando o Decreto 2.208 foi promulgado, havia no Brasil a possibilidade legal de integração entre ensino médio e educação profissional. Com este Decreto, essa possibilidade teve fim, e os sistemas de ensino tinham como alternativa para o ensino técnico, apenas as formas concomitante e sequencial. No primeiro caso, a formação técnica poderia ser feita durante o curso do ensino médio e, no segundo caso, após o término do ensino médio. Ambas as formas com currículos próprios e independentes do ensino médio, dito "regular". Essa determinação foi motivo de muitos debates e lutas por parte de educadores progressistas, defensores da integração entre ensino médio e educação profissional, de modo que, no ano de 2004, um novo Decreto foi promulgado em substituição ao anterior, mantendo as duas formas anteriores e possibilitando a integração entre ensino médio e educação profissional, sendo então possível com o novo Decreto, 5.154/04, ocorrer a formação profissional técnica sob as formas concomitante, subsequente e integrada. Essas determinações passaram a fazer parte da Lei de Diretrizes e Bases (LDB) 9.394/96 no ano de 2008, por meio da Lei 11.741, que acrescentou à LDB a Seção IV-A, intitulada Da Educação Profissional Técnica de Nível Médio, composta por quatro artigos específicos para a educação profissional técnica, até então inexistente na LDB.

A LDB passou então a possibilitar as duas formas que eram únicas no Decreto 2.208/97 e também o ensino médio integrado, forma esta que consiste em uma formação humana e profissional ao mesmo tempo e no mesmo curso. Destina-se a alunos concluintes do ensino fundamental, com matrícula única, na mesma instituição de ensino e mesmo curso, com currículo organizado de forma a conduzir o aluno à conclusão do ensino médio e a uma habilitação profissional, podendo este dar continuidade aos estudos e atuar profissionalmente.

As instituições de ensino são livres para ofertar ou não o ensino médio na forma integrada, exceto os Institutos Federais (IF) para os quais a Lei 11.892/08 que os criou, prevê que devem destinar metade de suas vagas totais à oferta de ensino médio integrado.

As lutas pelo ensino médio integrado trazem em suas bases elementos de uma educação integral pautada na formação politécnica ${ }^{4}$ e unitária ${ }^{5}$, mas não se confunde totalmente com elas, visto que a atual conjuntura social brasileira em que, para a maioria dos jovens, é necessário acelerar o ingresso no mercado de trabalho, a escolha profissional não ocorre após o término da educação básica. Diante dessa realidade e da necessidade de se buscar e implementar um caminho na direção da superação da dualidade estrutural existente entre educação básica e educação profissional, os setores envolvidos nos debates, nos estudos e na luta por tal superação, no embate de revogação do Decreto 2.208/97 que aprofundou a dualidade, optaram por,

[...] um tipo de ensino médio que garanta a integralidade da educação básica, ou seja, que contemple o aprofundamento dos conhecimentos científicos produzidos e acumulados historicamente pela sociedade, como também objetivos adicionais de formação profissional numa perspectiva da integração dessas dimensões [...] ao adotar a ciência, a tecnologia, a cultura e o trabalho como eixos estruturantes, contempla as bases em que se pode desenvolver uma educação tecnológica ou politécnica e, ao mesmo tempo, uma formação profissional stricto sensu, exigida pela dura realidade socioeconômica do país. (BRASIL, 2010, p. 18).

\footnotetext{
${ }^{4}$ Saviani (2011) discute a questão do uso do termo Politecnia. O autor salienta que, recentemente, surgiu a discussão de que essa expressão corresponderia a uma concepção burguesa de educação, visto que Marx haveria dado ênfase à educação tecnológica e não politécnica;, no entanto, Saviani ressalta que Marx utilizou a duas expressões indistintamente. Afirma ainda que o termo educação tecnológica foi apropriado pela burguesia ao passo que o termo politecnia passou a ser identificado à concepção socialista e por isso é rejeitado pela burguesia.

${ }^{5}$ A gênese da escola unitária proposta por Antonio Gramsci está em oposição à reforma da educação realizada pelo primeiro ministro da pública instrução na Itália no período fascista, Giovanni Gentile. O fundamento da escola unitária é superação da divisão entre trabalho manual e intelectual estabelecida pela divisão da sociedade em classes. O cerne da proposta está no confronto histórico entre ideias sobre o papel da escola de concepção humanista de inspiração iluminista, e, de outro, pela economicista (CARMO, 2008, 2011).
} 
Trata-se de uma solução "transitória e viável” (BRASIL, 2010, p. 18), necessária para se alcançar o horizonte da educação politécnica e unitária, a superação da dualidade entre ensino geral e técnico. Mas trata-se também de um tipo de educação combatida pelas forças conservadoras, por se tratar de uma formação integral que coloca, como centro, o sujeito e as dimensões fundamentais da sua sociabilidade, o que não condiz com o foco dessas forças, que é exclusivamente o mercado de trabalho.

As bases conceituais do ensino médio integrado almeja um sistema unificado que supere a dualidade, por meio "[...] de assegurar a articulação entre os conhecimentos e a produção" (SAVIANI, 2011, p. 319).

A discussão sobre a formação profissional e sobre o ensino médio na forma integrada nos remete inevitavelmente a discutir acerca do conceito trabalho. Comumente o termo trabalho é entendido como sinônimo de emprego e salário, mas seu sentido vai além deste, se observado sob outra ótica. O trabalho é a forma como os homens produzem suas existências e desse modo "[...] deriva o modo como se produz a educação" (SAVIANI, 2011, p. 131). Na sociedade atual em que vivemos, a produção da existência dos homens se realiza conforme o lugar em que ele ocupa na sociedade, se dono dos modos de produção ou se dono da força de trabalho.

Observa-se, portanto, que o trabalho pode ser assumido como princípio, tanto na perspectiva do capital, como do trabalhador. Do ponto de vista do trabalhador, o trabalho é categoria ontológica da práxis humana, como ocorria nas sociedades primitivas, onde trabalho e educação não se dissociavam, ocorriam simultaneamente. Do ponto de vista do capital, o trabalho é visto como mercadoria, atividade assalariada.

A categoria trabalho assume assim, duas dimensões distintas, a de trabalho como práxis humana, processo inerente ao ser humano, e como meio de subsistência do homem por meio da venda da sua força de trabalho, sob a forma de trabalho assalariado. O trabalho tem, portanto, duas dimensões, a histórica "[...] porque referido a um processo produzido e desenvolvido ao longo do tempo pela ação dos próprios homens" (SAVIANI, 2007, p. 155) e a dimensão ontológica porque é entendido como ação exclusivamente humana, na qual o "produto dessa ação, o resultado desse processo é o próprio ser dos homens" (SAVIANI, 2007, p. 155).

Se o trabalho é a forma de produção da existência humana, podemos concluir que "[...] o modo como o homem trabalha determina todas as demais formas da existência humana" (SAVIANI, 2011, p. 133).

A busca pela integração entre conhecimentos gerais e específicos leva o jovem a compreender como os princípios científicos se transformam em força produtiva no âmbito econômico, o que tem como consequência uma formação sólida capaz de levar o indivíduo a assumir postos de trabalho variados, sem necessidade de inserir-se em um curso de formação profissional pontual e pragmático, que tem como base o treinamento para uma única função.

\section{$4 \mathrm{O}$ ensino médio integrado no estado de Mato Grosso do Sul no Instituto Federal de Mato Grosso do Sul}

O IFMS é a primeira instituição ${ }^{6}$ da esfera federal a ofertar educação profissional técnica no estado, mais especificamente, o ensino médio integrado. Trata-se de uma instituição de "[...] educação superior, básica e profissional, pluricurriculares e multicampi [...]" (BRASIL, 2008) tendo como uma de suas finalidades "ministrar educação profissional técnica de nível médio, prioritariamente na forma de cursos integrados, para os concluintes do ensino fundamental [...]" (BRASIL, 2008) sendo que para atender a essa determinação deverão ser destinadas no mínimo $50 \%$ de suas vagas.

O IFMS possui sete unidades, nos municípios de Aquidauana, Campo Grande, Corumbá, Coxim, Nova Andradina, Ponta Porã e Três Lagoas. A primeira a iniciar as atividades foi a unidade de Nova Andradina no ano de 2010, com as primeiras turmas de alunos, as demais iniciaram no ano de 2011.

Os dados da Tabela 2, abaixo, mostram o quantitativo de matrículas no ensino médio e na educação profissional técnica no estado.

\footnotetext{
${ }^{6}$ Os Institutos Federais (IF) foram implantados no país no processo de expansão da Rede Federal de Educação, como parte dos objetivos do Plano de Desenvolvimento da Educação (PDE).
} 
O ensino médio integrado não aparece de modo específico, está contido no quantitativo do ensino médio. Os números referentes à área Educação Profissional Técnica se referem aos cursos técnicos, concomitante e subsequente:

Tabela 2 - Número de matrículas no Ensino Médio e na Educação Profissional Técnica de Nível Médio no Estado de Mato Grosso do Sul por dependência administrativa (2007- 2011).

\begin{tabular}{|ccccccccccc}
\hline & \multicolumn{1}{c}{ Ensino Médio } & \multicolumn{4}{c}{ Educação Profissional Técnica } \\
\hline Esfera & 2007 & 2008 & 2009 & 2010 & 2011 & 2007 & 2008 & 2009 & 2010 & 2011 \\
Estadual & 80.866 & 77.904 & 78.610 & 85.760 & 86.054 & 1.613 & 1.807 & 2.991 & 2.116 & 3.565 \\
Federal & 441 & 426 & 496 & 645 & 1.419 & 0 & 0 & 0 & 0 & 0 \\
Municipal & 104 & 112 & 115 & 104 & 128 & 0 & 0 & 0 & 0 & 0 \\
Total público & 81.411 & 78.442 & 79.221 & 86.509 & 87.601 & 1.613 & 1.807 & 2.991 & 2.116 & 3.565 \\
\hline Privada & 12.943 & 12.319 & 12.121 & 12.082 & 12.121 & 4.238 & 5.232 & 5.476 & 5.425 & 5.749 \\
\hline Total geral & 94.354 & 90.761 & 91.342 & 98.591 & 99.722 & 5.851 & 7.039 & 8.467 & 7.541 & 9.310 \\
\hline
\end{tabular}

Fonte: Instituto Nacional de Estudos e Pesquisas Educacionais Anísio Teixeira/ Sistema de Consulta a Matrícula do Censo Escolar 1997/2011. Disponível em: http:/ / portal.inep.gov.br/ basica-censo ${ }^{7}$

Mesmo não tendo acesso, por meio dos dados analisados, ao número exato de matrículas no ensino médio integrado especialmente na esfera estadual, é possível verificarmos as matrículas aproximadas na esfera federal, visto que o IFMS é a única instituição federal destinada a ofertar ensino médio integrado no estado. Assim, de 2007 a 2009, as matrículas que aparecerem na esfera federal se referem ao Colégio Militar de Campo Grande, que não é parte da Rede Federal de Educação Profissional e Tecnológica, mas do sistema federal de ensino, e não oferece ensino médio integrado. A partir do ano de 2010, as matrículas dessa esfera, no estado se referem tanto ao Colégio Militar como ao IFMS. Segundo os Editais de Processo Seletivo do IFMS 4/2010, $12 / 2010$ e $8 / 2011$, foram abertas 120 vagas em 2010, e 1120 em 2011. No entanto foram preenchidas apenas 93 vagas, segundo informações $^{8}$ do próprio INEP.

É possível também identificar o número de matrículas do ensino médio integrado da esfera municipal, pois a única escola a ofertar esse tipo de ensino médio nessa esfera no estado é a Escola Agrícola Governador Arnaldo Figueiredo na capital do estado. As matrículas referentes ao ensino médio integrado da esfera estadual não podem ser

\footnotetext{
${ }^{7}$ Dados adquiridos no site oficial do INEP: http:/ / portal. inep.gov.br/basica-censo.

${ }^{8}$ As informações foram enviadas por e-mail, após solicitação por meio do site oficial do INEP: <http:// portal.inep.gov.br/institucional-faleconosco $>$, por Clodoaldo de Oliveira Lemes <clodoaldo.lemes@inep. gov.br> em 4 de fevereiro de 2013.
}

identificadas na Tabela, no entanto é sabido que oito municípios ${ }^{9}$ do estado ofertam ensino médio integrado na rede estadual de ensino, segundo dados apresentados no site da Secretaria de Estado de Educação de Mato Grosso do Sul (SED/MS).

A Tabela 2 mostra ainda que as matrículas em cursos profissionais sejam concomitantes, sejam subsequentes passaram de menos de 6.000 em 2007 para quase 10.000 em 2011, no total geral. Em 2007, o setor público atendeu 27, 5\% das matrículas da Educação Profissional Técnica, enquanto em 2011 esse percentual aumentou para 38, 2\%. No ano de 2004, o Plano Estadual de Educação de Mato Grosso do Sul (MATO GROSSO DO SUL, 2004), com vigência até o ano de 2010, faz observações sobre a educação profissional no estado, apontando como seus principais problemas a predominância da esfera privada na oferta de cursos, a falta de docentes habilitados

\footnotetext{
${ }^{9}$ Os municípios que ofertam ensino médio integrado no estado de Mato Grosso do Sul na Rede Estadual, segundo o site oficial da Secretaria de Estado de Educação: <http://www.sed.ms.gov.br/index.php?i nside $=1 \&$ tp $=3 \&$ comp $=\&$ show $=4165>$, são: Amambai (duas escolas com oferta de dois cursos: Informática e Agropecuária); Bela Vista (uma escola com oferta do curso Informática); Campo Grande: (cinco escolas com oferta de cinco cursos: Informática; Rede de computadores; Manutenção e Suporte em Informática; Administração e; Meio Ambiente); Dourados (duas escolas com dois cursos: Agropecuária e Marketing); Iguatemi (uma escola com a oferta do de Informática); Ivinhema (uma escola e um curso: Agropecuária); Paranaíba (uma escola com um curso: Informática) e; São Gabriel do Oeste (uma escola e um curso: Informática).
} 
para atuar e a insuficiência entre a demanda regional e a oferta de cursos técnicos.

O IFMS, ao elaborar o seu Plano de Desenvolvimento Institucional (PDI), no ano de
2009 fez um levantamento sobre a demanda regional e apresentou uma projeção de abertura de vagas para o ensino médio integrado de 2010 a 2014:

\begin{tabular}{|cccccc|}
\hline \multicolumn{7}{c}{ Tabela 3 - Vagas previstas para o ensino médio integrado no IFMS } & (2010- 2014) \\
\hline Unidade & $\mathbf{2 0 1 0}$ & $\mathbf{2 0 1 1}$ & $\mathbf{2 0 1 2}$ & $\mathbf{2 0 1 3}$ & $\mathbf{2 0 1 4}$ \\
\hline Aquidauana & 320 & 640 & 960 & 1280 & 1600 \\
Campo Grande & 480 & 960 & 1440 & 1920 & 2400 \\
Corumbá & 480 & 960 & 1440 & 1920 & 2400 \\
Coxim & 320 & 640 & 960 & 1280 & 1600 \\
Nova Andradina & 320 & 640 & 800 & 960 & 960 \\
Ponta Porã & 320 & 640 & 960 & 1280 & 1600 \\
Três Lagoas & 320 & 640 & 960 & 1280 & 1600 \\
Total & 2560 & 5120 & 7250 & 9920 & 12.160 \\
\hline
\end{tabular}

Fonte: Plano de Desenvolvimento Institucional (PDI/IFMS, 2009).

Vejamos agora a Tabela 4 que demonstra o quantitativo de vagas abertas mediante editais de seleção no IFMS:

Tabela 4 - Vagas abertas nos cursos de ensino médio integrado pelo IFMS (2010 -2013)

\begin{tabular}{|ccccc|}
\hline Unidade & $\mathbf{2 0 1 0}$ & $\mathbf{2 0 1 1}$ & $\mathbf{2 0 1 2}$ & $\mathbf{2 0 1 3}$ \\
\hline Aquidauana & 0 & 160 & 80 & 80 \\
\hline Campo Grande & 0 & 240 & 120 & 240 \\
\hline Corumbá & 0 & 160 & 80 & 80 \\
Coxim & 0 & 160 & 80 & 80 \\
\hline Nova Andradina & 120 & 160 & 80 & 80 \\
\hline Ponta Porã & 0 & 160 & 80 & 160 \\
\hline Três Lagoas & 0 & 1120 & 600 & 80 \\
\hline Total & 120 & & 80 & 800 \\
\hline
\end{tabular}

Fonte: Editais de processo seletivo IFMS: 4/2010; 12/2010; 8/2011, 9/2012.

Os dados apresentados na Tabela 4 demonstram as vagas que foram abertas, no entanto podemos inferir que tais vagas podem não ter sido todas preenchidas, a exemplo do que ocorreu no ano de 2010, quando os editais 4/2010 e 12/2010 abriram 120 vagas, mas somente 93 foram ocupadas.

Os dados expostos nas Tabelas 2, 3 e 4 revelam que há demanda por educação profissional técnica no estado, mas, em se tratando de ensino médio integrado, embora consideremos a implantação do IFMS e dos cursos de ensino médio integrado no estado um avanço no sentido de que não dispúnhamos de instituições dessa natureza até a sua implantação, as matrículas não avançaram conforme o previsto pela demanda inicial. Uma das explicações para esse fato é a entrada no estado, a exemplo do cenário nacional, do Pronatec, criado no ano de 2011 com as seguintes iniciativas: a) expansão da Rede Federal; b) expansão da oferta de cursos nas redes estaduais por meio do Programa Brasil Profissionalizado; c) investimento na formação à distância por meio da Rede E-TecBrasil; d) oferta de cursos por meio do SENAI, Serviço Nacional de Aprendizagem Comercial (SENAC), Serviço Social do Comércio (SESC) e Serviço Social da Indústria (SESI); e) promoção do financiamento por meio do FIES, de cursos técnicos em instituições privadas e do Serviço Nacional de Aprendizagem; f) oferta de Bolsa- Formação para estudantes matriculados nos cursos.

Os objetivos e as iniciativas do Pronatec são claros, a nova política de formação profissional pretende entrar em todas as esferas administrativas, desde as escolas estaduais de ensino médio às da rede federal, com forte articulação com a iniciativa privada. 
Os cursos ofertados por esse programa são cursos que, de certo modo, independem da formação básica e podem ser vistos como estratégias para retirar o ensino médio integrado de foco, pois criam o consenso de que basta um curso rápido, de algumas horas, que o sujeito estará apto a atuar no mercado de trabalho. O que se deve levar em conta é que se trata de uma formação aligeirada e com fins pontuais para atender a uma necessidade imediata do mercado, e não à formação integral do ser para atuar na vida profissional e social.

A questão que levantamos não é a de que não se devem fazer tais cursos, mas procuramos ir um pouco além das necessidades pontuais dos indivíduos de busca pela sua sobrevivência no contexto do sistema capitalista. Esses cursos buscam atender a essas necessidades dos jovens e trabalhadores brasileiros enquanto seus direitos de pleno desenvolvimento não só como profissional, mas como ser social e histórico, ficam à margem das políticas de governo.

Enquanto o ensino médio integrado busca a formação integral do sujeito e tem vistas à superação da realidade dada, por meio de uma formação que integre conhecimentos gerais e específicos, os cursos do Pronatec surgem com proposições que praticamente ignoram qualquer tipo de escolaridade, com treinamentos rápidos e pontuais. O Guia Pronatec de cursos FIC $^{10}$ (2013) elaborado pelo Ministério da Educação (MEC) tem como objetivo o direcionamento da oferta dos cursos e traz atualmente um total de 644 cursos.

A Tabela 5 mostra o número de cursos FIC do Pronatec segundo a sua carga horária e segundo a escolaridade exigida:

Tabela 5 - Carga horária e escolaridade mínima exigida pelos cursos Pronatec

\begin{tabular}{lccccc} 
Carga horária & \multicolumn{2}{c}{ Total de cursos segundo a escolaridade (em unidades) } \\
\cline { 2 - 6 } (em horas) & $\begin{array}{c}\text { Ensino } \\
\text { fundamental I } \\
\text { incompleto }\end{array}$ & $\begin{array}{c}\text { Ensino } \\
\text { fundamental II } \\
\text { incompleto }\end{array}$ & $\begin{array}{c}\text { Ensino } \\
\text { fundamental } \\
\text { completo }\end{array}$ & $\begin{array}{c}\text { Ensino médio } \\
\text { incompleto }\end{array}$ & $\begin{array}{c}\text { Ensino } \\
\text { médio } \\
\text { completo }\end{array}$ \\
De 160 a 240 & 109 & 290 & 116 & 27 & 42 \\
\hline De 250 a 400 & 9 & 14 & 27 & 2 & 8 \\
\hline Total geral & \multicolumn{7}{c}{644} & & \\
\hline
\end{tabular}

Fonte: Guia Pronatec de cursos FIC. 3. ed. 2013. Disponível em: http:// pronatec.mec.gov.br/fic/.

A Tabela 5 revela que os cursos do Pronatec se voltam para um público com ensino fundamental incompleto e têm cargas horárias pequenas, indo de 160 horas, até 240 horas predominantemente, revelando assim, o seu caráter pragmático, pontual e com foco apenas no treinamento para uma atividade profissional, totalmente distante da educação básica. Essas características levam os sujeitos a terem que realizar o maior número de cursos possíveis a fim de estarem aptos a atuar no mercado de trabalho por estarem "qualificados", uma vez que a formação desses cursos não oferece subsídios suficientes para a atuação profissional em um vasto campo, mesmo que sejam postos de trabalho do mesmo campo.

O Pronatec, ao ter como campo de atuação todas as esferas administrativas, inseriu-se também no IFMS, "atravessando" a política de oferta de ensino médio integrado no seu âmbito. Hoje este oferece cursos de FIC e concomitantes, vinculados a esse programa. Atualmente, são 26 cursos de FIC e quatro concomitantes no estado, enquanto são apenas 10 cursos de ensino médio integrado ofertados nessa mesma instituição (IFMS, 2009-2013) atendendo a menos de 2.000 mil matrículas até o ano de 2012.

Uma recente reportagem veiculada na mídia local, intitulada Pronatec integra Senai, Senac e IFMS na qualificação de alunos do Ensino Médio no Estado, revelou que são oferecidas 12.340 vagas em 138 cursos, em catorze municípios do estado de Mato Grosso do Sul. Isso ilustra como essa política tem se alastrado no estado estancando de forma mais forte as possibilidades de expansão do ensino médio integrado.

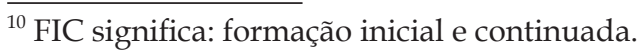


Em Os riscos do Pronatec para a educação técnica profissional, documento da Diretoria Executiva da Confederação Nacional dos Trabalhadores em Educação (CNTE, 2011), são traçados alguns dos riscos oferecidos pelo Pronatec: a) a falta de dimensionamento do papel do Estado na oferta pública e gratuita de educação profissional técnica; b) a flexibilização do compromisso do Estado e o estímulo à reserva de mercado educacional, colidindo, portanto, com o recente cenário de expansão do direito à educação pública e gratuita; c) contraposição do acordo feito em 2008 do governo federal com o sistema $S$ de expandir as matrículas gratuitas no âmbito desse sistema, isso porque com o Pronatec essas instituições ao invés de ofertarem a gratuidade das vagas, receberão investimentos públicos do chamado, bolsa-formação trabalhador prevista no Pronatec; d) inibição da expansão de instituições públicas, compromissadas com a formação cidadã, isso porque os recursos públicos não são aplicados exclusivamente nas instituições públicas; e) reducionismo curricular, ou seja, as premissas do Decreto 5.154/04 e posteriormente da Lei 11.741/08 de integrar a formação profissional com a formação geral, objetivando o desenvolvimento dos estudantes para a vida produtiva e social, por meio do ensino médio integrado passam a ser substituídas pela formação de curta duração; f) condicionamento do trabalhador assistido por seguro-desemprego ao vínculo empregatício sem direito de escolha, isso porque o Pronatec altera as legislações do programa seguro-desemprego e seguridade social, condicionando as parcelas deste à comprovação de frequência em cursos de qualificação profissional.

Não é difícil perceber que o Pronatec traz toda uma articulação em favor das instituições privadas, representadas pelo chamado Sistema S. Segundo Rodrigues (1998) as décadas 1980 e 1990 foram palco de consolidação da entrada do empresariado brasileiro nos debates e elaboração das políticas educacionais, fato este que as levou a serem elaboradas de modo geral, para atender as necessidades pontuais da esfera produtiva em expansão, ou seja, conforme se move a economia, se exige um determinado tipo de trabalhador para atender a esse movimento. Segundo o autor, essa participação e influência do empresa- riado nas questões educacionais ocorreram por meio da "[...] articulação do binômio modernização-qualificação profissional" (p. 5) sendo representada, na política educacional de formação profissional pela atuação da Confederação Nacional da Indústria (CNI), sendo este "[...] o mais importante órgão de representação da burguesia industrial brasileira [...]" (RODRIGUES, 1998) atuando com o que chama de tríade pedagógica do Sistema CNI “[...] Serviço Nacional de Aprendizagem Industrial (SENAI), Serviço Social da Indústria (SESI), e pelo Instituto Euvaldo Lodi (IEL)" (RODRIGUES, 1998, p. 7).

\section{Considerações finais}

O campo do ensino médio e suas relações com a educação profissional técnica é minado por interesses distintos, que se movem e produzem contradições. Não por acaso observamos na história, a separação entre essas áreas com o Decreto 2.208/97 seguido pelas lutas dos setores progressistas por mais de dez anos, até a promulgação do Decreto 5.154/04, seguido da Lei 11.741/08 que insere o conteúdo do Decreto na LDB, assegurando de modo mais sólido, em termos legais, a oferta do ensino médio integrado.

Embora haja a base legal para oferta de ensino médio integrado, essa não é a única forma de relacionar a educação básica à educação profissional, desse modo, os embates e os distintos interesses, predominando os interesses dos setores conservadores da sociedade, continuam vivos e perpassando os documentos e as políticas educacionais para o ensino médio e educação profissional. De um lado, há a defesa de treinamento de mão de obra para atender ao setor produtivo, com forte expressão hoje no Pronatec. De outro lado, a busca pela formação da pessoa humana como um todo, levando em conta também as necessidades da maioria dos jovens que, na atual conjuntura social brasileira, precisam precocemente ingressar no mercado de trabalho.

Dessa forma, defendemos que o ensino médio integrado dever-se-ia transformar em política de Estado, a ser implantada em todas as redes de ensino, em todo o Brasil, visto que esta é " [...] condição necessária para se fazer a 'travessia' para uma nova realidade 
[...]" (FRIGOTTO; CIAVATTA; RAMOS, 2005, p. 19).

O estado de Mato Grosso do Sul tem uma dívida com a educação profissional pública e gratuita, visto que a esfera privada sempre predominou nessa área. A implantação do IFMS trouxe para o estado a abertura das possibilidades de oferta de ensino médio integrado, ainda que tenhamos até o atual momento um número irrisório de matrículas neste, se considerado o total de matrículas no ensino médio.

Pretendemos com este texto, iniciar os debates acerca da função dos cursos de ensino médio integrado no estado e abrir flancos para a ampliação dos debates nessa área, considerando que o estado não tem uma trajetória histórica de educação profissional técnica, como outros estados que, desde 1909, quando do surgimento da rede federal já iniciaram a sua consolidação nessa área.

A forte presença do agronegócio no estado traz a necessidade de futuras pesquisas nessa área, a fim de verificar a disputa que se coloca hoje no âmbito desse modelo de agricultura e suas relações com a educação e a formação de mão de obra para o mercado de trabalho e a educação integral, unitária e politécnica.

Enquanto houver diferenças entre redes de ensino e qualidade de ensino nestas, estaremos a passos mais distantes do horizonte do ensino médio integrado: a educação politécnica e unitária. Tal diferenciação acaba por definir o "lugar" na divisão do trabalho: enquanto as redes privadas preparam para os vestibulares, seus estudantes ficam privilegiados em ocupar cargos de direção, visto que a sua condição socioeconômica não os obriga a precocemente ingressar no mercado de trabalho; os privilegiados em ingressar no ensino médio integrado na rede federal receberão formação acadêmica provida de conhecimentos científicos e tecnológicos atrelados aos conhecimentos gerais e ocuparão os postos de trabalho mais qualificados, enquanto os que recebem formação concomitante e subsequente, geralmente oferecida pelas redes estaduais, ou seja, de treinamento, ocuparão os postos de trabalho menos qualificados, bem como os que se qualificam via Pronatec. Como já mencionado, a crítica ao modelo de formação profissional desvinculada da educação básica, é voltada para o seus perfis de políticas de governo. O que defendemos é uma educação integral que considere o sujeito na sua integralidade e, nesse sentido, o ensino médio integrado é a solução mais viável para a atual conjuntura social.

\section{Referências}

ABREU, Silvana de. Planejamento governamental: a Sudeco no espaço mato-grossense contexto, propósitos e contradições. 2001. Tese (Doutorado em Geografia Humana) - Faculdade de Filosofia, Letras e Ciências Humanas, Universidade de São Paulo, São Paulo, 2001.

AZEVEDO, José Roberto Nunes de. Expansão da agroindústria canavieira no Mato Grosso do Sul: relação capital x trabalho e reconfiguração espacial. 2008. Dissertação (Mestrado em Geografia) - Faculdade De Ciências Humanas, Universidade Federal da Grande Dourados, Dourados, MS, 2008.

BRASIL. Lei de Diretrizes e Bases da Educação n. 9.394 de 20 de dezembro de 1996. Brasília: Senado Federal, 2007.

. Decreto 2.208 de 17 de abril de 1997. Regulamenta o $\$ 2^{\circ}$ do art. 36 e os artigos 39 a 42 da Lei 9.394 , de 20 de dezembro de 1996, que estabelece as diretrizes e bases da educação nacional . Disponível em: <http:/ / portal.mec.gov>. Acesso em: 2 jun. 2011.

Decreto 5.154 de 23 de julho de 2004. Regulamenta o $\S 2^{\circ}$ do art. 36 e os arts. 39 a 41 da Lei n. 9.394 de 20 de dezembro de 1996, que estabelece as diretrizes e bases da educação nacional, e dá outras providências. Disponível em: <http:/ / www.planalto.gov.br >. Acesso em: 2 jun. 2011.

. Lei n. 11.741 de 16 de julho de 2008. Altera dispositivos da Lei no 9.394, de 20 de dezembro de 1996, que estabelece as diretrizes e bases da educação nacional, para redimensionar, institucionalizar e integrar as ações da educação profissional técnica de nível médio, da educação de jovens e adultos e da educação profissional e tecnológica. Disponível em: <http:/ / www.planalto. gov.br/ccivil_03/_Ato2007 2010/2008/Lei/L11741. htm\#art2>. Acesso em: 12 dez. 2011.

Diretrizes Curriculares Nacionais para a Educação Profissional Técnica de Nível Médio em Debate. Texto para discussão. Brasília, 2010. Disponível em: <www.mec.gov.br>. Acesso em: 16 de mar. 2012.

. Lei n. 11.892 de 29 de dezembro de 2008. Institui a Rede Federal de Educação Profissional, Científica e Tecnológica, cria os Institutos Federais e dá outras providências. Disponível em: <http://www.planalto. gov.br/ccivil_03/_Ato2007-2010/2008/Lei/L11892. htm>. Acesso em: 3 jun. 2011.

CARMO, Jefferson Carriello do. Algumas aproximações sobre trabalho, escola e educação no pensamento de Antonio Gramsci. Revista Reflexão e Ação, Santa Cruz do Sul, RS, v. 19, n. 1, p. 140-164, jan./jun. 2011.

Notas sobre a escola unitária e trabalho no pensamento de Antonio Gramsci. Cadernos Cemarx, Campinas, SP, n. 5, p. 53-63, 2008.

CONFEDERAÇÃONACIONAL DOS TRABALHADORES EM EDUCAÇÃO - CNTE. Os riscos do Pronatec 
para a educação técnica profissional. Revista Retratos da Escola, Brasília, v. 5, n. 8, p. 179-184, jan./jun. 2011. Disponível em: <http//www.esforce.org.br>. Acesso em: 2 maio 2013.

FEDERAÇÃO DA AGRICULTURA E PECUÁRIA DE MATO GROSSO DO SUL. - FAMASUL. Análise das classes de renda rural em Mato Grosso do Sul. Artigo técnico, Campo Gande, MS, 2012. Disponível em: <http:/ / famasul.com.br/public/download-pdf/673-arquivo. pdf>. Acesso em: 2 maio 2013.

FRIGOTTO, Gaudêncio; CIAVATTA, Maria; RAMOS, Marise. A gênese do Decreto n. 5.154/2004: um debate no contexto controverso da democracia restrita. In: FRIGOTTO, Gaudêncio; CIAVATTA, Maria; RAMOS, Marise. Ensino médio integrado: concepção e contradições. São Paulo: Cortez, 2005.

GALERA, Mauricio Martorelli. A inserção dos frigoríficos exportadores de Mato Grosso do Sul no mercado global. 2011. Dissertação (Mestrado em Geografia) - Faculdade de Ciências Humanas, Universidade Federal da Grande Dourados, Dourados, MS, 2011.

INSTITUTO FEDERAL DE MATO GROSSO DO SUL - IFMS. Plano de Desenvolvimento Institucional. Mato Grosso do Sul, 2009.

Edital n. 04/2010 - Exame de seleção para o $2^{\circ}$ semestre do ano letivo de 2010 para os cursos de educação profissional técnica de nível médio integrado e para os cursos de educação profissional técnica de nível médio integrado, na modalidade educação de jovens e adultos (proeja), ofertados no campus Nova Andradina. Disponível em: <http:/ / www.ifms.edu.br/ wp-content/uploads/2010/05/edital_04_2010_examede-seleção_ifms.doc.pdf>. Acesso em: 10 maio 2013.

Edital n. 12/10 - Exame de seleção para o $1^{\circ}$ semestre do ano letivo de 2011 para os cursos de educação profissional técnica de nível médio integrado e cursos de educação profissional técnica de nível médio integrado na modalidade de educação de jovens e adultos (PROEJA). Disponível em: <http:/ / www.ifms. edu.br/wp-content/uploads/2010/11/edital-exameseleção_versãofinal1.pdf>. Acesso em: 10 maio 2013.

Edital n. 008/2011 - PROEN/IFMS. Exame de seleção para o $1^{\circ}$ semestre do ano letivo de 2012 para os cursos de educação profissional técnica de nível médio integrado e cursos de educação profissional técnica de nível médio integrado na modalidade de educação de jovens e adultos (PROEJA). Disponível em: <http:// www.ifms.edu.br/wp-content/uploads / 2011/11/ edital-008.2011-proen-ifms-exame-de-seleção.pdf>. Acesso em: 10 maio 2013.

. Edital n. 009/2012 - PROEN/IFMS. Exame de seleção para o $1^{\circ}$ semestre do ano letivo de 2013 para os cursos de educação profissional técnica de nível médio integrado e cursos de educação profissional técnica de nível médio integrado na modalidade de educação de jovens e adultos (PROEJA). Disponível em: <http:// www.ifms.edu.br/wp-content/uploads / 2012/12/ edital-009.2012-edital-exame-de-seleção-2013.pdf>. Acesso em: 10 maio 2013.

LEITE, Sergio Pereira; MEDEIROS, Leonilde Servolo. Agronegócio. In: CALDART, Roseli Salete; PEREIRA, Isabel Brasil; ALENTEJANO, Paulo; FRIGOTTO, Gaudêncio (Org.). Dicionário da educação do campo. Rio de Janeiro/São Paulo: Escola Politécnica de Saúde Joaquim Venâncio/Expressão Popular, 2012.

MATO GROSSO DO SUL (Estado). Plano Estadual de Educação de Mato Grosso do Sul. 2004. Disponível em: $<$ http:/ / www.sed.ms.gov.br/index.php?inside=1\&tp $=3 \&$ comp $=\&$ show $=446>$. Acesso em: 5 abr. 2012.

POCHMANN, Marcio. A batalha pelo primeiro emprego: as perspectivas e a situação atual do jovem no mercado de trabalho. São Paulo: Publisher Brasil, 2000.

PRONATEC INTEGRA SENAI, SENAC E IFMS NA QUALIFICAÇÃO DE ALUNOS DO ENSINO MÉDIO NO ESTADO. 2013. Disponível em: <http://www. feitoms.com.br/component/content/article/42-destaque-capa/758-pronatec-integra-senai-senac-e-ifmsna-qualificacao-de-alunos-do-ensino-medio-no-estado. html>. Acesso em: 11 maio 2013.

RODRIGUES, José. O moderno príncipe industrial: o pensamento pedagógico da Confederação Nacional da Indústria. Campinas, SP: Autores Associados, 1998.

SAVIANI, Dermeval. Educação em diálogo. Campinas, SP: Autores Associados, 2011.

Trabalho e educação: fundamentos ontológicos e históricos. Revista Brasileira de Educação, Rio de Janeiro, v. 12, n. 34, p. 152-180, jan./abr. 2007. 